\begin{tabular}{cc}
$\begin{array}{c}\text { Yanbu Journal } \\
\text { of } \\
\text { Engineering } \\
\text { and Science }\end{array}$ & Vol. 5, October $2012(1433 \mathrm{H})$ \\
\hline \hline ISSN: $1658-5321$ & www.yjes.org.sa
\end{tabular}

\title{
COMBINED EFFECTS OF JOULE HEATING AND VISCOUS DISSIPATION ON TRANSIENT MHD NATURAL CONVECTION OF VISCOELASTIC FLUID OVER A VERTICAL SURFACE
}

\author{
Mohammed Q. Al-Odat ${ }^{1,2}$ Abdulamjeed Saeed Al-Ghamdi ${ }^{2}$ and Abdullah H. AlEssa ${ }^{3}$ \\ ${ }^{I}$ Mechanical Engineering Department, Al-Huson University College, Al-Balqa Applied University, Irbid, Jordan \\ Email:m_alodat@yahoo.com \\ ${ }^{2}$ Department of Mechanical Engineering, Umm Al-Qura University, Makkah, Saudi Arabia \\ ${ }^{3}$ Mechanical Engineering Department, College of Engineering, Northern Border University, Saudi Arabia
}

\begin{abstract}
The combined effects of Joule heating and viscous dissipation on transient Magnetohydrodynamics (MHD) free convective flow of an incompressible electricallyconducting viscoelastic second-order fluid over a vertical surface are investigated numerically. The governing non-linear dimensionless equations are solved using an implicit finite difference scheme of Crank-Nicolson type with a tri-diagonal matrix manipulation. Effects of viscoelastic parameter, Magnetic parameter, Eckert number and Prandtl number on the flow and heat transfer transient characteristics are studied. It was found that, the velocity inside the boundary layer increases as the viscoelastic parameter increases, and accordingly the skin friction coefficient increases. Conversely an opposite behavior is observed for the temperature profiles.
\end{abstract}

Keywords: Transient, MHD free convection, Viscoelastic fluid, Viscous dissipation, Joule heating, Numerical solution.

\section{INTRODUCTION}

Free convective flow of viscoelastic fluid has attracted the attention of several researchers in recent years due to its extensive applications in various engineering processes. The study of such heat and fluid flow is very important theoretically and practically. Theoretically, flow of viscoelastic fluids are basic in fluid flow and heat transfer. Practically, flows of this fluid type is essential in manufacturing of polymeric sheets, paper production, manufacturing processes of artificial films and fibers, thermoplastic sheet production and many others. For example Abel et al. [1] investigated the influences of viscous dissipation and non-uniform heat source/sink on the boundary layer flow and heat transfer characteristics of a second grade fluid through pours medium. Ahmad et al. [2] conducted a mathematical analysis of heat transfer effect on the axisymmetric flow of second grade viscoelastic fluid over a stretching sheet using the homotopy method. Transient flow and heat transfer with viscous dissipation of a non-Newtonian fluid over unsteady stretching sheet was investigated by Chen [3]. Cortell [4] studied the fluid flow and heat transfer in an incompressible second order fluid caused by a stretching sheet. Hayat et al. [5] constructed an analytical solution for the flow of second grade fluid on an oscillating porous plate. Recently, Arnold at al. [6] investigated heat transfer in viscoelastic boundary layer flow over a stretching sheet. Duwairi et al. [7] examined the viscoelsatic boundary layer flow 
and the heat transfer near a vertical isothermal impermeable surface and in a quiescent fluid. All the above research works found that the velocities increase inside the hydrodynamic boundary layers and the temperatures decrease inside the thermal boundary layers for the viscoelsatic fluid as compared with the Newtonian

The study the Magnetohydrodynamics flows and heat transfer (MHD) of viscoelastic fluids has received, through the years, a growing attention because of its crucial applications in engineering, agriculture, petroleum industries, geophysics and astrophysics. The magnetic field is one of the most important parameters applied to alter the momentum and heat transfer characteristics in viscoelatic fluids. Ariel [8] studied the laminar flow of a viscoelastic fluid past a stretching sheet in the presence of a magnetic field, when the fluid is extracted from the sheet at a uniform rate. Khan and Pop [9] invesitaged numerically, the unsteady boundary layer free convection flow of an incompressible electrically conducting viscoelastic second-order fluid over a vertically permeable flat plate, where temperature and concentration differences are responsible for the convective buoyancy current. A comprehensive theoretical analysis of a two-dimensional unsteady free convection flow of an incompressible, viscoelastic fluid past an infinite vertical porous plate was conducted by Chowdhury and. Islam [10]. Mostafa [11] considered the influences of radiation and temperaturedependent viscosity on the problem of unsteady MHD flow and heat transfer of an electrically conducting fluid past an infinite vertical porous plate taking into account the effect of viscous dissipation. Hsiao [12] analyzed the heat and mass transfer of a steady laminar boundary-layer flow of an electrically magnetic conducting fluid of second grade subject to suction and to a transverse uniform electromagnetic field past a semi-infinite stretching sheet. Chen [13] examined the combined effects of Joule heating and viscous dissipation on the momentum and thermal transport for the MHD flow over a stretching sheet. Zueco et al. [14-15] implemented a mathematical model to study the unsteady MHD natural convection flow of a viscoelastic fluid over an infinite vertical porous plate to an isotropic, homogeneous, non-Darcian porous media, with timedependent suction. Babaelahi [16] studied the momentum and heat transfer steady state charateristics of an incompressible electrically conducting viscoelastic fluid over a stretching surface with viscous and Ohmic dissipations. Mahantesh [17] carried out an analysis to study the flow and heat transfer characteristics for MHD viscoelastic boundary layer flow over an impermeable stretching sheet with space and temperature dependent internal heat generation/absorption, viscous dissipation, thermal radiation and magnetic field. Gord et al. [18] presented an analysis of the twodimensional steady-state incompressible viscoelastic boundary layer MHD flow and heat transer over a stretching sheet. Alharbi et al. [19] studied the convective heat and mass transfer charateristics of an incompreesible electrically conducting viscoelastic fluid over over a stretching sheet with chemical reaction and stratification effects. Banerjee et al. [20] considered the unsteady heat transfer effect due to a sudden introduction of heat source/sink on a steady viscous boudary layer MHD flow and heat transfer over a linearly stretching sheet subjected to a constant temperature. Recently, Olajuwon [21] examined the steady state heat and mass transfer in a hydrodynamic flow of a second grade fluid past a stretching sheet in the 
presence of thermal radiation and thermal diffusion.

It is worth mentioning that the majority of these studied were focused on steady state characteristics. In contrast, transient fluid flow and heat problems of viscoelastic have received little attention. This is because that the transient heat transfer is usually difficult to solve either analytically or numerically. In fact there is no actual flow situation, which does not involve unsteadiness, and examples of transient convective flows are numerous including cooling of electronic devices in which the heat generation is not constant but time varying.

In view of the above literature review, the objective of present article is to study the heat transfer characteristics of a two-dimensional transient MHD free convective of an electrically conducting second grade viscoelastic fluid over a heated vertical plate taking into account Joule heating and viscous dissipation effects. The governing non-linear partial differential equations are solved by using an implicit finite difference method of Crank-Nicolson type. The influences of viscoelastic, magnetic and viscous dissipation parameters on the transient behaviors of the velocity and temperature as well as skin friction coefficient and Nusselt number were analyzed.

\section{PROBLEM FORMULATION AND MATHEMATICAL ANALYSIS}

There are very wide classes of viscoelastic fluid models. However, the most used model is the second grade fluid has following the constitutive relation [22]:

$$
\mathbf{T}=-p \mathbf{I}+\mu \mathbf{A}_{1}+\alpha_{1} \mathbf{A}_{2}+\alpha_{2} \mathbf{A}_{1}^{2}
$$

Where $\mathbf{T}$ is the Cauchy stress tensor, $p$ is the pressure, $\mathrm{I}$ is the coefficient viscosity, $\mu$ is the classical coefficient of dynamic viscosity, $\alpha_{1}$ and $\alpha_{2}$ are the normal stress moudlii, $\mathbf{A}_{1}$ and $\mathrm{A}_{2}$ are the kinematic tensor definded as:

$$
\begin{aligned}
& \mathbf{A}_{1}=(\operatorname{grad} \mathbf{V})+(\operatorname{grad} \mathbf{V})^{\mathrm{T}} \\
& \mathbf{A}_{2}=\frac{D \mathbf{A}_{1}}{D t}+\mathbf{A}_{1}(\operatorname{grad} \mathbf{V})+(\operatorname{grad} \mathbf{V})^{\mathrm{T}} \mathbf{A}_{1}
\end{aligned}
$$

Where $\mathrm{V}$ is the velocity field, grad is is the gradient operator, $\mathrm{T}$ is the transpose, and $\frac{D}{D t}$ is the substantial time derivative. The normal stress moudli $\alpha_{1}$ and $\alpha_{2}$ are crossponding to the first and second normal stresses, $\mathrm{N}_{1}$ and $\mathrm{N}_{2}$, respectively. The reported experimental data for large numbers of viscoelastic fluids indicated that $\mathrm{N}_{1}$ is positive. Whereas, $\mathrm{N}_{2}$ can be positive, negative or zero. Moreover, the values of $\mathrm{N}_{1}$ were found to be much greater than $\mathrm{N}_{2}$. In order to meet the experimental behavior of the viscoelastic fluid, one should have $\alpha_{1}>0$ and $\alpha_{2} \leq 0$. It is worth mentioning that there are some controversies about this rheological model, principally the sign of $\alpha_{1}$ and $\alpha_{2}$. For thermodynamic reasons, the material parameters $\alpha_{1}$ must be positive. If a second grade fluid modeled by Eq. (1) is to be compatible with thermodynamics and is to satisfy the ZluasiusDuhem inquality for all motions and the aasumption that the specific Helmholtz free enegry of the fluid is a minimum when it is locally at rest, then [22]

$\mu \geq 0, \quad \alpha_{1} \geq 0$, and $\quad \alpha_{1}+\alpha_{2}=0$

In the present investigation the viscoelastic fluid is assumed to thermodynamically compatible. The $x$-axis is taken along the vertical plate in the upward direction and the $y$-axis is taken normal to the plate. The continuity and the momentum equations for the problem at hand can be written as

$$
\begin{aligned}
& \frac{\partial u}{\partial x}+\frac{\partial \mathrm{v}}{\partial y}=0 \\
& \rho\left(\frac{\partial u}{\partial t}+u \frac{\partial u}{\partial x}+\mathrm{v} \frac{\partial u}{\partial y}\right)=-\frac{\partial p}{\partial x}+\frac{\partial^{2} \tau_{x x}}{\partial x}+\frac{\partial^{2} \tau_{x y}}{\partial x} \\
& \rho\left(\frac{\partial \mathrm{v}}{\partial t}+u \frac{\partial \mathrm{v}}{\partial x}+\mathrm{v} \frac{\partial \mathrm{v}}{\partial y}\right)=-\frac{\partial p}{\partial y}+\frac{\partial^{2} \tau_{y x}}{\partial x}+\frac{\partial^{2} \tau_{y y}}{\partial x}
\end{aligned}
$$


Applying the boundary layer approximations; (i.e. $x=O(1), u=O(1), \quad$ and $\mathrm{v}=O(\delta)$ ) the $y$-momentum equation reduces to $\partial p / \partial y=0$. Now, consider the transient two-dimensional MHD free convection flow of an electricallyconducting viscoelastic fluid over an isothermal vertical plate under a transverse uniform magnetic field. The problem at hand is described in cartesian coordinate system attached to the plate, with $x$-axis along the plate and the $y$-axis is perpendicular to the plate. Initially (at $t \leq 0)$ the plate and the viscoelastic fluid are at the same constant temperature $T_{\infty}$ at all points. For timet $>0$, the plate temperature is suddenly raised to $T_{w}$ $\left(>T_{\infty}\right)$. It is assumed that, the fluid properties are constant except the influence of density variation with temperature which is considered only in the body force term. Viscous dissipation and Joule heating are taken into consideration. Under these assumptions along with Boussinesq approximation, the governing equations are given by

$\frac{\partial u}{\partial x}+\frac{\partial \mathrm{v}}{\partial y}=0$

$\frac{\partial u}{\partial t}+u \frac{\partial u}{\partial x}+\mathrm{v} \frac{\partial u}{\partial y}=v \frac{\partial^{2} u}{\partial y^{2}}+g \beta\left(T-T_{\infty}\right)$

$-k_{o}\left(\begin{array}{l}\frac{\partial^{3} u}{\partial y^{2} \partial t}+u \frac{\partial^{3} u}{\partial x \partial y^{2}}+\mathrm{v} \frac{\partial^{3} u}{\partial y^{3}} \\ -\frac{\partial u}{\partial y} \frac{\partial^{2} u}{\partial x \partial y}+\frac{\partial u}{\partial x} \frac{\partial^{2} u}{\partial y^{2}}\end{array}\right)-\frac{\sigma B_{0}{ }^{2}}{\rho} u$

$\frac{\partial T}{\partial t}+\mathrm{u} \frac{\partial T}{\partial x}+\mathrm{v} \frac{\partial T}{\partial y}=\alpha \frac{\partial^{2} T}{\partial y^{2}}+$

$\frac{\mu}{v c_{P}}\left(\frac{\partial u}{\partial y}\right)^{2}+\frac{\sigma B_{0}}{\rho c_{P}} u^{2}$

Equation (8) is a third order partial differential equation of the dependent variable $u$, therefore, three boundary conditions on $u$ are required to obtain a unique solution for the equation. A crucial review on the boundary conditions and the existence and uniqueness of the solution was reported by Rajaopal et al. [23-24]. Most of the reported works on the boundary layer flow of viscoelastic fluid employ the boundary conditions on the velocity, which are less than the required conditions to solve the problem uniquely by one. The initial and boundary conditions for the velocity, temperature and concentration fields are given by:

$$
\begin{gathered}
\text { at } t \leq 0: u=0, \mathrm{v}=0, T=T_{\infty} \text { for } x \geq 0, y \geq 0 \\
\text { at } t>0: u=0, \mathrm{v}=0 T=T_{w}, \text { for } y=0, x \geq 0 \\
: u=0, \frac{\partial u}{\partial y}=0, \mathrm{v}=0, T=T_{\infty}, \text { as } y \rightarrow \infty \\
: u=0, \mathrm{v}=0, T=T_{\infty} \text { for } x=0, y \geq 0
\end{gathered}
$$

Where $u$ and $\mathrm{v}$ are the averaged velocity components along the $x$ and $y$, directions respectively, $t$ is the time, $T$ is the temperature, $\beta$ is the thermal expansion coefficient and the concentration expansion coefficient respectively, $v$ is the kinematic viscosity, Bo is the magnetic field strength, $\sigma$ is the electrical conductivity, $\alpha$ is the thermal diffusivity, $c_{P}$ is the specific heat at constant pressure and $k_{o}=\frac{-\alpha_{1}}{\rho}$ is the viscoelastic parameter. The additional boundary condition on $\mathrm{u}\left(\frac{\partial u}{\partial y}=0,\right)$ is added in order to determine the momentum boundary layer.

To write non-dimensional form of the governing equations the following dimensionless quantities ar introduced:

$$
\begin{aligned}
& X=\frac{x}{L}, \quad Y=\frac{G r^{\frac{1}{4}} y}{L}, \quad \tau=\frac{v t}{\sqrt{G r} L^{2}}, \\
& U=\frac{L u}{\sqrt{G r} v}, \quad \mathrm{~V}=\frac{v G r^{\frac{1}{4}} \mathrm{v}}{L}, \quad \theta=\frac{T-T_{\infty}}{T_{W}-T_{\infty}}, \\
& M=\frac{\sigma B_{0}^{2} L^{2}}{\rho v \sqrt{G r}}, \quad E c=\frac{v^{2} G r}{c_{P} L^{2}\left(T_{W}-T_{\infty}\right)}, \\
& G r=\frac{g \beta L^{3}\left(T_{W}-T_{\infty}\right)}{v^{2}}, \quad \operatorname{Pr}=\frac{v}{\alpha}
\end{aligned}
$$

Therefore, using the above dimensionless quantities, the governing equations (7-9) are 
reduced to the following non-dimensional form

$$
\begin{aligned}
& \frac{\partial U}{\partial X}+\frac{\partial \mathrm{V}}{\partial Y}=0 \\
& \frac{\partial U}{\partial \tau}+U \frac{\partial U}{\partial X}+\mathrm{V} \frac{\partial U}{\partial Y}=\frac{\partial^{2} U}{\partial Y^{2}}- \\
& K\left(\begin{array}{l}
\frac{\partial^{3} U}{\partial Y^{2} \partial \tau} U \frac{\partial^{3} U}{\partial X \partial Y^{2}}+\mathrm{V} \frac{\partial^{3} U}{\partial Y^{3}} \\
-\frac{\partial U}{\partial Y} \frac{\partial^{2} U}{\partial X \partial Y}+\frac{\partial U}{\partial X} \frac{\partial^{2} U}{\partial Y^{2}}
\end{array}\right)+\theta-M U \\
& \frac{\partial \theta}{\partial \tau}+\mathrm{U} \frac{\partial \theta}{\partial X}+\mathrm{V} \frac{\partial \theta}{\partial Y}=\frac{1}{\operatorname{Pr}} \frac{\partial^{2} \theta}{\partial Y^{2}}+ \\
& E c\left(\frac{\partial U}{\partial Y}\right)^{2}+(M E c) U^{2}
\end{aligned}
$$

and the corresponding initial and boundary conditions in dimensionless form can be written as

$$
\begin{aligned}
& \text { at } \tau \leq 0: U=0, \mathrm{~V}=0, \theta=0, \text { for } X \geq 0, Y \geq 0 \\
& \text { at } \tau>0: U=0, \mathrm{~V}=0, \theta=1 \text {, for } Y=0, X \geq 0 \\
& : U=0, \frac{\partial U}{\partial Y}=0, \mathrm{~V}=0, \theta=0, \text { as } Y \rightarrow \infty \\
& : U=0, \mathrm{~V}=0 \quad \theta=0 \quad \text { at } X=0, Y \geq 0
\end{aligned}
$$

where $\tau$ is the dimensionless time, $K$ is the viscoelastic parameter, Ec is the Eckert number, $M$ is the magnetic field parameter and $P r$ is Prandtl number.

After, the velocity and temperature fields are computed; it is customary to study the skin friction coefficient and rate of heat transfer. Given the velocity field in the boundary layer the skin friction coefficient can be written as

$$
C_{f} G r^{\frac{3}{4}}=\left(\frac{\partial U}{\partial Y}\right)-2 K\left(\frac{\partial U}{\partial Y}\right)\left(\frac{\partial V}{\partial Y}\right) \text { at }(\tau, X, 0)
$$

Knowing the temperature field, the rate of heat transfer coefficient can be obtained in terms of Nusselt number as

$$
N u G r^{-\frac{1}{4}}=-\left(\frac{\partial \theta}{\partial Y}\right)_{(\tau, X, 0)}
$$

\section{NUMERICAL SOLUTION}

The unsteady, non-linear, coupled partial differential equations (12)-(14) together with their boundary and initial conditions (15) are solved numerically using an implicit finitedifference technique of Crank-Nicolson type. The computational domain is taken as a rectangle of width $1\left(X_{\max }\right)$ and length of 6 $\left(Y_{\max }\right)$, where $Y_{\max }$ corresponds to $Y=\infty$, which lies very well outside the momentum and thermal, boundary layers. The maximum value of $Y$ was chosen after some preliminary investigations, so that the boundary conditions are satisfied with a tolerance of $10^{-6}$. After experimenting with a few set of mesh sizes, the mesh sizes have been fixed at the level $\Delta X=0.01$ and $\Delta Y=0.05$, with a time step $\Delta \tau=0.005$ The results obtained using a finer grid do not reveal discernible changes in the predicted heat transfer and flow fields. Thus, due to computational cost and accuracy considerations the above mesh size was considered as an optimum for the present computations.

The iteration error $(\varepsilon)$, in percentage form has been defined as follows

$\varepsilon=\left|\frac{f_{i, j}^{n+1}-f_{i, j}^{n}}{f^{n+1}{ }_{i, j}}\right| \times 100 \%$

where $f$ stands for $U, V$ and $\theta$, $n$ refers to time and $i, j$ refers to space coordinates. The value of $\varepsilon$ is chosen as 10-6.

An examination of data for unsteady solution revealed little or no change in $\mathrm{U}, \mathrm{V}$ and $\theta$ after $\tau=1$ for all computations. Thus, the result for $\tau=1$ are taken as essentially the steady state values.

In order to verify the accuracy of the present computer code, particular results are compared with those available in the literature. The unsteady results without Joule heating and viscous dissipation are compared with those of Ref. [7]. Fig. (1) displays this comparison, it can be seen that the agreement between the results is excellent. This has established confidence in the numerical results to be reported in this article. 


\section{RESULTS AND DISCUSSION}

A parametric study is conducted to study the effects of all parameters involved on the transient velocity and temperature profiles as well as the transient skin friction coffiencient and Nusselt numbers. Theses effects are discussed in the subsequent sections.

\subsection{EFFECTS OF THE VISCO-ELASTIC PARAMETER $K$}

Figures (2a) and (2b) show the transient velocity and temperature distributions respectively for chosen values of the viscoelastic parameter K. These figures reveal that an increase in the visco-elastic parameter leads to a corresponding increase in the velocity profiles. This is consistent with the fact that the thickness of the momentum boundary layer occurs due to the presence of nonNewtonian visco-elastic normal stress. The values of these profiles are higher for a viscoelastic fluid than for a Newtonian fluid $(K=0)$. Therefore, the thickness of the velocity boundary layer for a viscoelastic fluid is higher than for a Newtonian fluid. Also, it is observed that the momentum boundary layer thickness increases as time elapses. Hence, an increase in $\mathrm{K}$ clearly enhances the streamwise velocity, $\mathrm{U}$ which ascends sharply and peaks in close vicinity to the plate surface $(\mathrm{Y}=0)$. With increasing spanwise coordinate the velocity profiles decay smoothly to zero in the freestream at the edge of the boundary layer. Meanwhile, an opposite behaviour can be observed for the temperature profiles as shown in Fig. (2b). Increasing viscoelasticity $\mathrm{K}$ is seen to slightly decrease temperature throughout the boundary layer. As the free stream is approached the effects of viscoelasticity are negligible since the profiles are all merged together. All profiles decay from the maximum at the wall to zero in the free stream. The graphs display therefore that increasing viscoelasticity cools the flow. With progression of time, however the temperature, $\theta$ is consistently enhanced i.e. the fluid is heated as time progresses. This behavior reflects the coupling of the energy equation to the momentum equation through the temperature dependent body forces resulting from the free convection. In addition the velocity, temperature increases as time passes and the momentum and thermal boudary layers grow up with time.

The influence of viscoelastic parameter on the transient characteristics of the local skin friction and Nusselt are illustrated in in Fig. (3). the shear stress is clearly reduced with increasing viscoelasticity (stronger elastic effects) i.e. the flow is accelerated, a trend consistent with the earlier computations in Fig. (2a). The effects of viscoelastic parameter on shear stress are very small at early time stages of the heat transfer process and this effect grows up with time. Increasing viscoelasticity $(\mathrm{K})$ is observed to enhance local Nusselt number values, whereas they are again decreased with greater time.

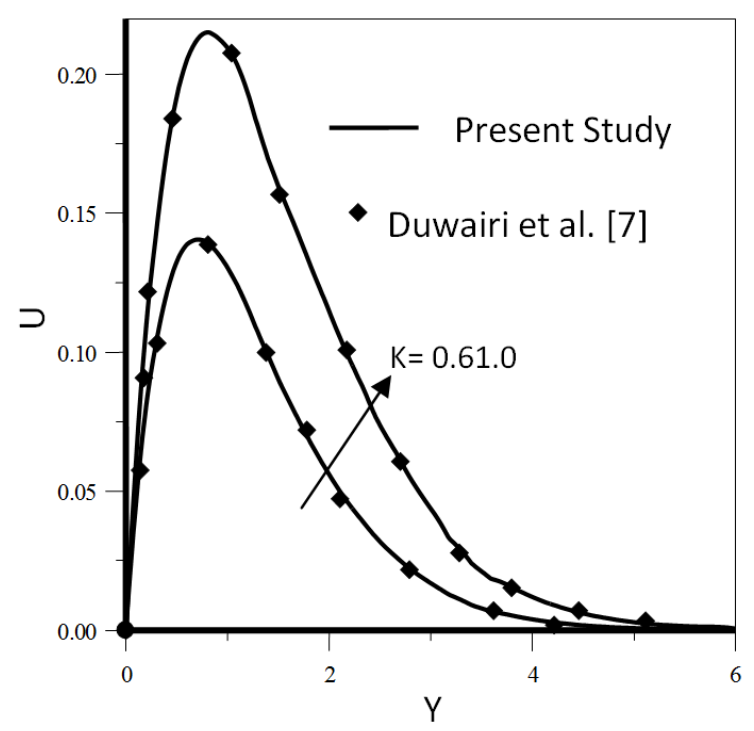

Fig.1 Comparison of steady-state velocity distributions of the present work with those of Ref. [7]. 


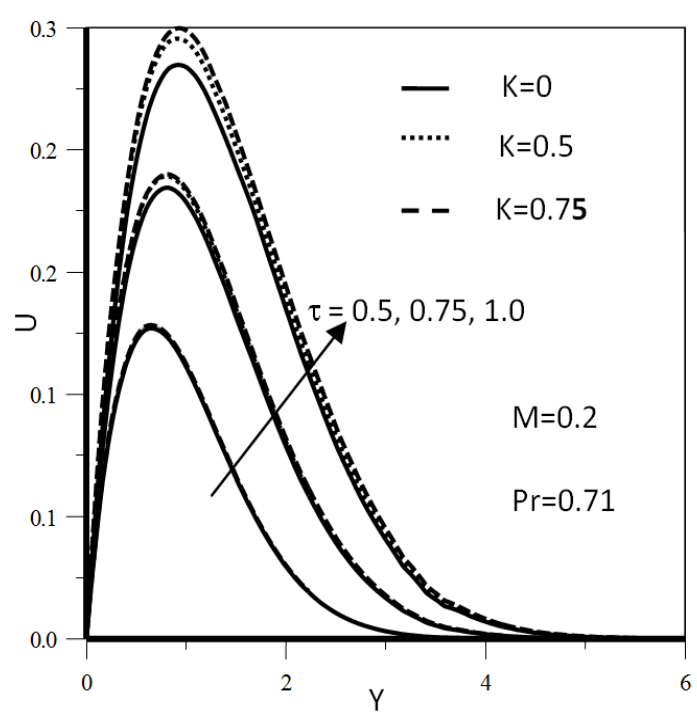

Fig. 2a Effects of Viscoelastic parameter on transient velocity distributions.

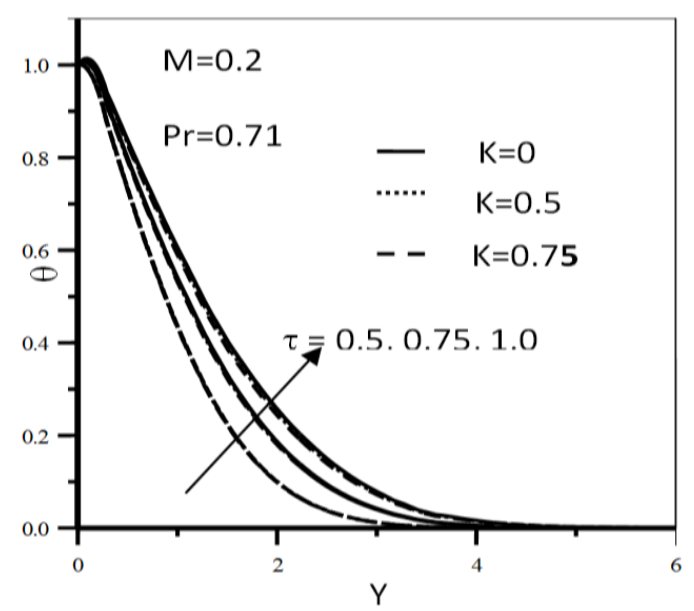

Fig. 2b Effects of Viscoelastic Paramter transient dimensionless temperature distrubutions.

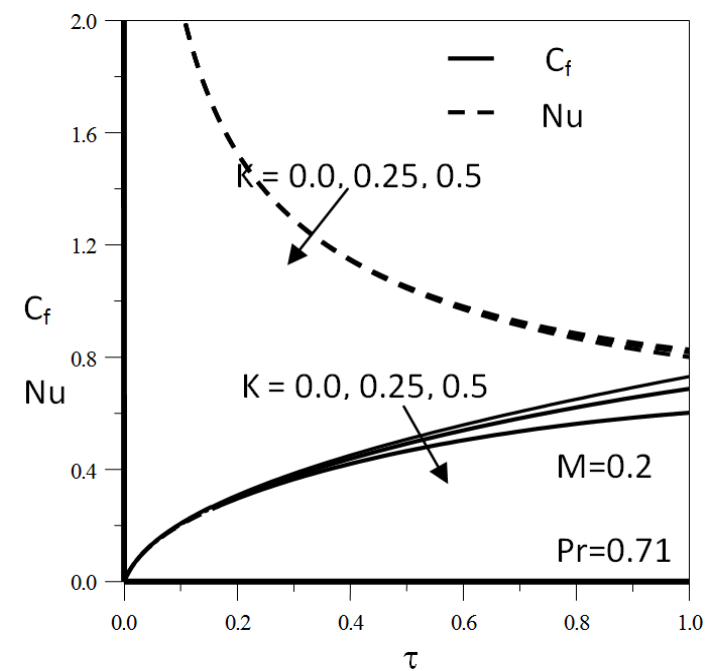

Fig. 3 Influences of Viscoelastic Parameter on Friction factor and Nusselt number histories.

\subsection{EFFECTS OF THE MAGNETIC PARAMETER M}

The effects of magnetic parameter on the transient velocity and temperature distributions, are plotted in Figs. (4a) and (4b) respectively. It is found that the effect of Magnetic field Parameter $M$ is to reduce the velocity profiles. This graphical representation reveals that Magnetic field Parameter $M$ decreases the velocity profiles, significantly in the visco-elastic flow, this is due to the fact that increase of $M$ signifies the increase of Lorentz force, which opposes the flow in the reverse direction and hence decelerates the fluid. Also, the velocity is increasing with time and the hydrodynamics boundary layer thicknesses are gradually increases with time. Increasing the magnetic field parameter is slightly raising the the temperature inside the boundary layer (see Fig. (4b)

Figure (5) illustrates the influence of magnetic parameter $(\mathrm{M})$ on the time variation of the skin friction coefficient, and the local Nusselt number. It can be seen that the the skin friction coefficient decreases as the magnetic parameter increases. In contrast, the heat transfer coeffiecient is slightly improved by increasing the $(\mathrm{M})$.

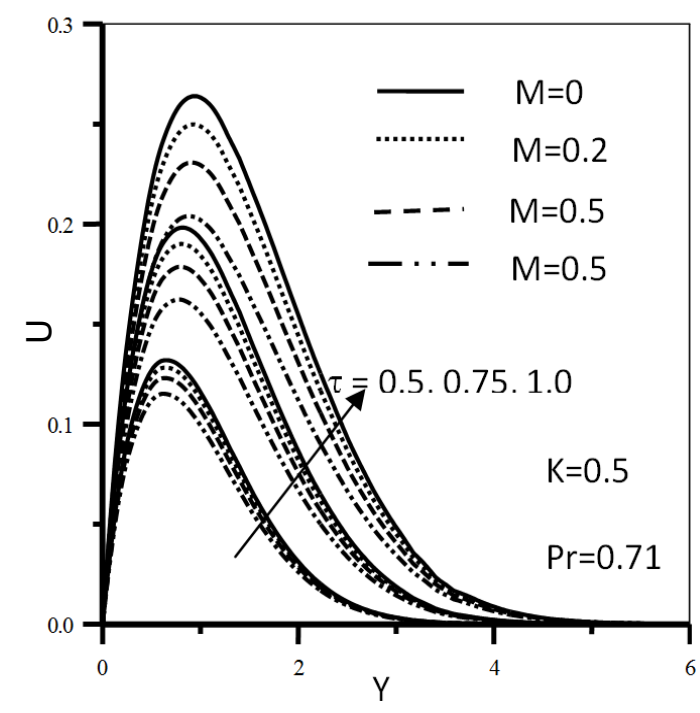

Fig. 4a Effects of Magnetic parameter on transient velocity distributions. 


\subsection{EFFECTS OF ECKERT NUMBER (EC)}

The influences of Eckert number (Ec) on the transient velocity, and temperature profiles are displayed in Figs. (6a) and (6b), respectively. Larger viscous dissipation causes a rise in the temperature as well as in the velocity profiles. As expected, temperature at a point increases with increasing $(\mathrm{Ec})$ because the heat energy is stored in the liquid due to the frictional heating and an overshoot in temperature ( $\mathrm{T}>$ $\mathrm{Tw}$ ) occurs near plate wall temperature before it decreased to the stream value.

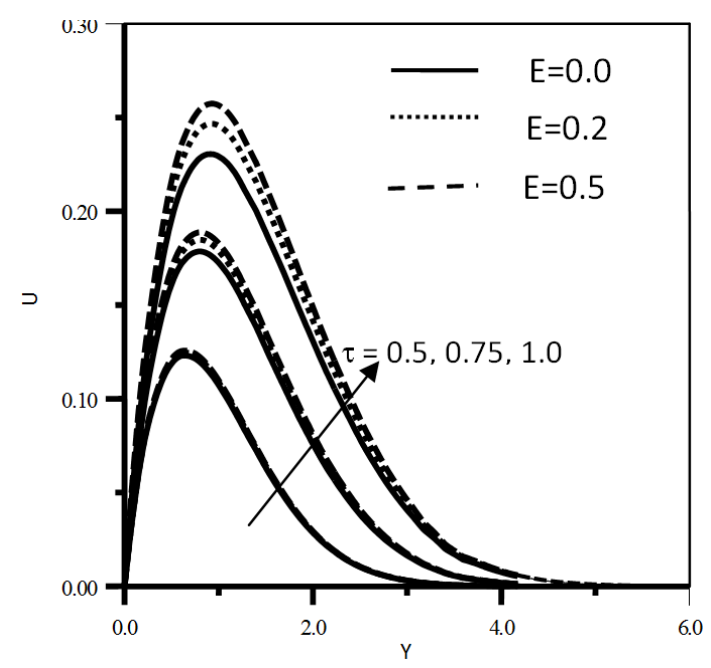

Fig. 6a Effects of Eckert number on transient velocity distrubutions.

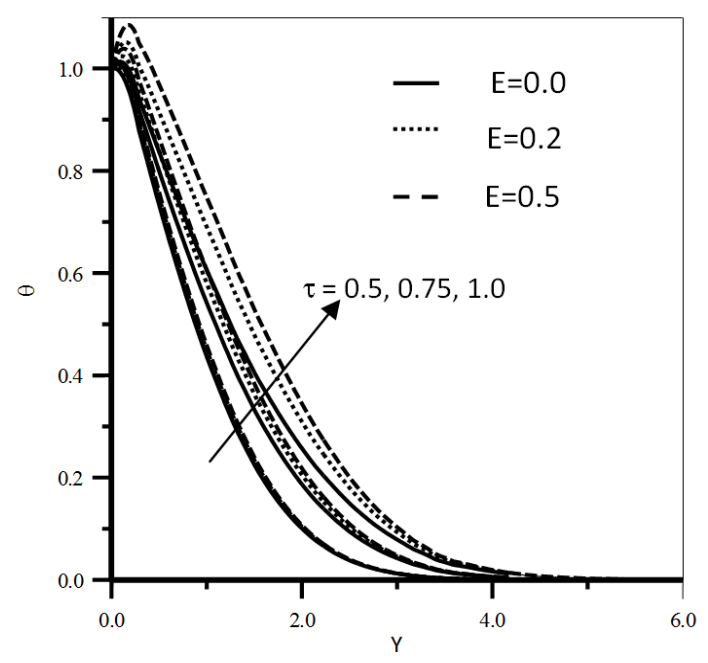

Fig. 6b Effects of Eckert number on transient temperature distrubutions.
This temperature represents the energy dissipated as thermal energy by viscous effects (i.e. work done by the viscous fluid in overcoming internal friction). Positive values of $(\mathrm{Ec})$ correspond to plate cooling when heat is lost from the plate to the fluid; negative values imply the plate heating wherein heat is transferred from the fluid to the plate. This study is concentrated on the former case. Ec also appears in the Joule (Ohmic) heating hydromagnetic term in equation (14). Moreover, it is clear that all temperature profiles decay asymptotically from a maximum wall temperature $(\theta=1)$ to zero in the free stream. Maximum fluid temperature in the boundary layer therefore is associated with the maximum (Ec) value, which is physically valid since greater thermal energy is generated in the fluid for larger $(\mathrm{Ec})$ values.

Fig. (7) demonstrates the effect of viscous disspiation parameter $(\mathrm{Ec})$ on the time evolution of skin friction coeffiecient and heat transfer rates. At early stages of the heat transfer process the effects of $(\mathrm{Ec})$ on skin friction and heat transfer rate are insignificant. Wheraas, the heat transfer rate is dramatically increases at the final time stages of the process.

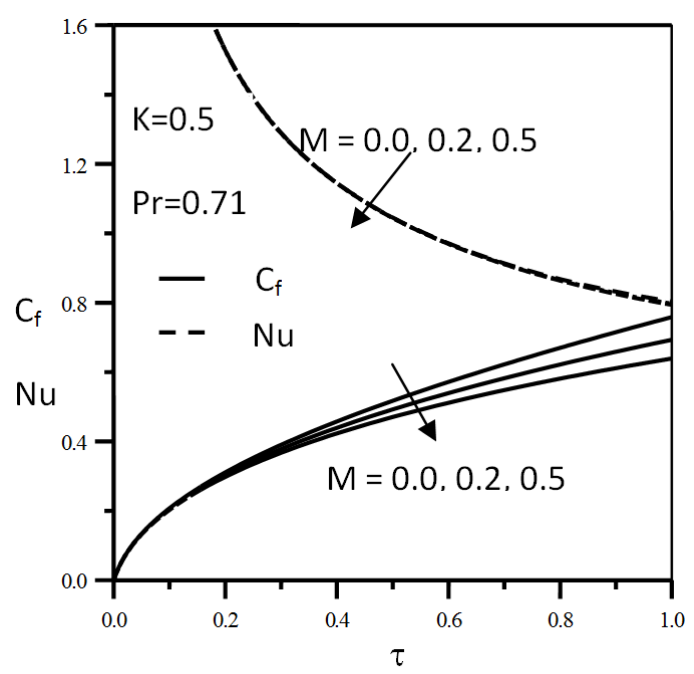

Fig. 7 Influences of Eckert number on Friction factor and Nusselt number histories. 


\subsection{EfFects of Prandtl NUMber (PR)}

The transient velocity and temperature profiles at different values of Prandtl number are illustrated in Figs. (8a) and (8b), respectively. The values of the Prandtl number are chosen for air $(\operatorname{Pr}=0.71)$, electrolytic solution $(P r=1.0)$, water $(P r=7.0)$, and water at $4{ }^{\circ} \mathrm{C}(\operatorname{Pr}=11.40)$. It can be noticed that an increase in Prandtl number results in a dramatic decrease in both the velocity and temperature profiles. This is because the Prandtl number can be increased by either increase of kinematic viscosity or decrease of thermal conductivity of the viscoelastic fluid. Smaller values of $(\mathrm{Pr})$ are correspondent to increase the thermal conductivity viscoelastic fluid and hence heat is able to diffuse away from the heated surface more promptly.

Figs. (9a) and (9b) show the influence of Prandtl number on local skin friction and local Nusselt number, respectively. The skin friction and the Nusselt number are dramatically reduced as the $\operatorname{Pr}$ values increases. The heat transfer rate in terms of Nusselt number is improved for larger values of $\operatorname{Pr}$ as shown in Fig. (9b). Furthermore, Nusselt number decreases rapidly with and more time is required to reach the steady state heat transfer rate for larger values of Pr. However the skin friction coefficient is increasing with time.

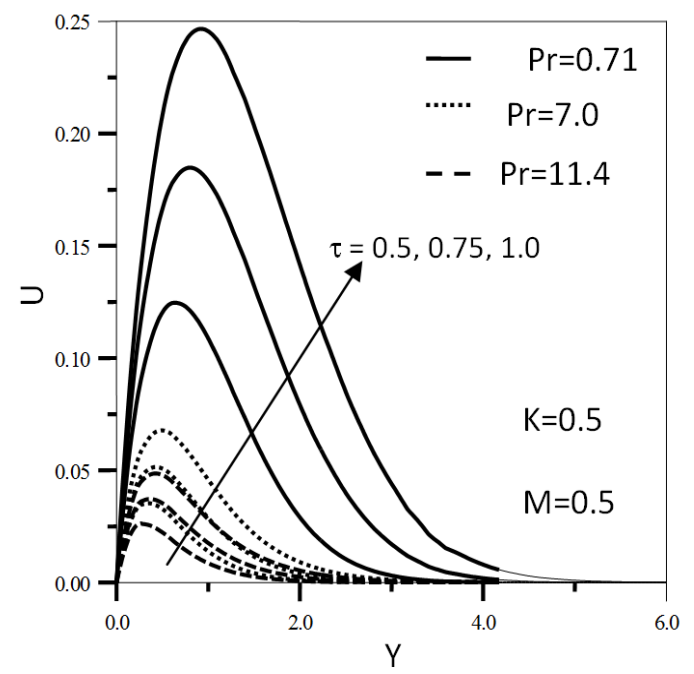

Fig. 8a Influences of Prandtl number on transient velocity profiles.

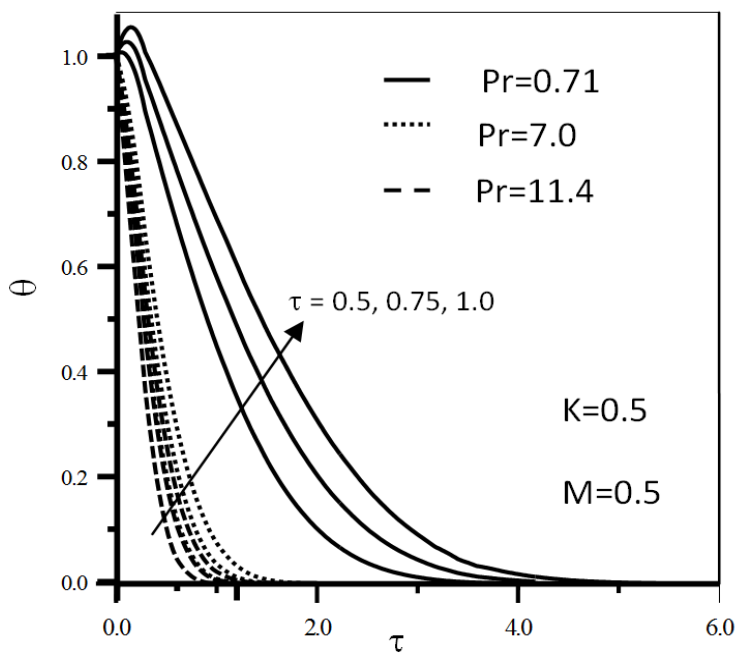

Fig. 8b Influences of Prandtl number on on transient temperature profiles.

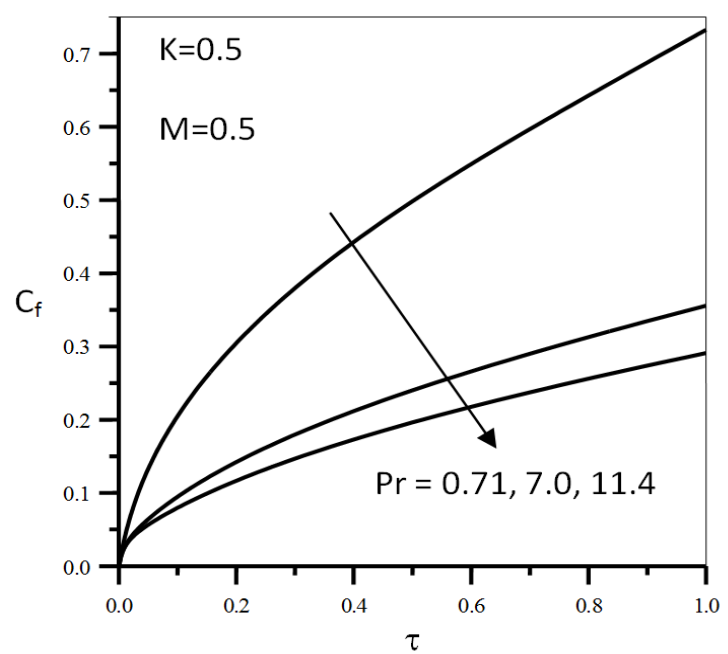

Fig. 9a Influences of Prandtl number on Friction factor time variation.

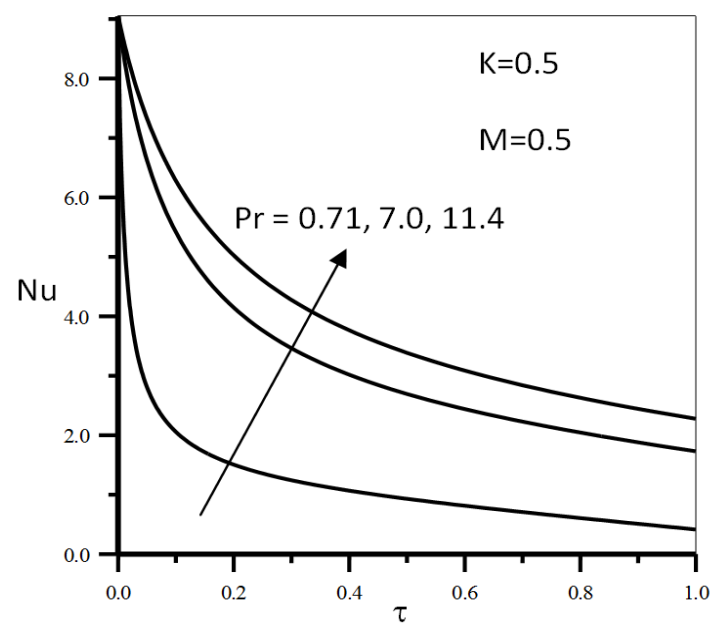

Fig. 9b Influences of Prandtl number on Nusselt number time variation. 


\section{CONCLUSION}

Finite difference investigation has been carried out to study the effect of Joule heating and viscous dissipation on unsteady MHD natural convection of an electrically conducting viscoelastic fluid over a flat plate. The dimensionless governing equations are solved by a finite difference method of CrankNicolson type. The present numerical results are compared with the previously reported data and the agreement is found to be excellent. It was found that the transient velocity distributions increase when the value of viscoelastic parameter, $K$ is increased while the opposite behaviour is observed for the temperature profiles. Moreover, when the viscoelastics parameter, $K$ increases it reduces the skin friction and increase the heat transfer rate. The results of this study show that the Joule heating and viscous dissipation have a significant effect on transient characteristics of the fluid flow and heat transfer of viscoelastic fluids.

\section{NOMENCLATURE}

Bo magnetic induction

$c_{p} \quad$ specific heat at constant pressure

Ec Eckert number

$g$ gravitational acceleration

$\mathrm{Gr}$ thermal Grashof number

$k$ thermal conductivity

$K \quad$ viscoelastic parameter

$k_{O} \quad$ viscoelastic parameter

$M \quad$ magnetic field parameter

$\mathrm{Nu} \quad$ Nusselt number

Pr Prandtl number

$T$ temperature

$t$ time

$T_{\infty} \quad$ free stream temperature

$T_{w} \quad$ wall temperature

$U, V$ dimensionless velocity components in $X$ and $Y$-directions, respectively

$u, \mathrm{v} \quad$ velocity components in $x$ and $y$-directions respectively
X dimensionless spatial coordinate along the plate

$x \quad$ spatial coordinate along the plate

$Y \quad$ dimensionless spatial coordinate normal to the plate

y spatial coordinate normal to the plate

\section{Greek Letters}

$\alpha \quad$ thermal diffusivity

$\alpha_{1}, \alpha_{2}$ normal stress moudlii

$\mu \quad$ dynamic viscosity

$\rho \quad$ fluid density

$\theta \quad$ dimensionless temperature

$\tau \quad$ dimensionless time

$v \quad$ kinematic viscosity

$\sigma \quad$ electrical conductivity

$\beta \quad$ coefficient of thermal expansion

\section{Subscripts}

$w \quad$ conditions at the wall

$\infty \quad$ free stream conditions

\section{REFERENCES}

[1] M. Subhas Abel; Mahantesh M. Nandeppanavar;M.B.Malkhe, Hydromagnetic Boundary Layer Flow And Heat Transfer In Viscoelastic Fluid over a Continuously Moving Permeable Stretching Surface with Nonuniform Heat Source/Sink Embedded in Fluid-Saturated Porous Medium, Chemical Engineering Communications, Vol.197 (5), pp. 633 - 655, (2010).

[2] I. Ahmad, M. Sajid, T. Hayat, Heat transfer in unsteady axisymmetric second grade fluid, Applied Mathematics and Computation, 215 pp. 1685-1695, (2009).

[3] Chien-Hsin Chen, Effect of viscous dissipation on heat transfer in a non-Newtonian liquid film over an unsteady stretching sheet, Journal of Non-Newtonian Fluid Mechanics, Vol. 135(2-3), pp. 128-135, (2006).

[4] Rafael Cortell, Flow and heat transfer of an electrically conducting fluid of second grade over a stretching sheet subject to suction and to a transverse magnetic field, International Journal of Heat and Mass Transfer, Vol.49(11-12), pp. 1851-1856, (2006) 
[5] T. Hayat1, , M. R. Mohyuddin , S. Asghar, and A. M. Siddiqui, The flow of a viscoelastic fluid on an oscillating plate, ZAMM . Z. Angew. Math. Mech. 84 (1), pp. 65 - 70 (2004).

[6] J. Charles Arnold, A. Alwyn Asir, S. Somasundaram and T. Christopher, Heat transfer in a viscoelastic boundary layer flow over a stretching sheet, International Journal of Heat and Mass Transfer, Vol. 53(5-6) pp. 1112-1118, (2010).

[7] H. M. Duwairi, R. A. Damseh, A. J. Chamkha, M. S. Abdel-Jaber, Transient free convection flow of a viscoelastic fluid over vertical surface , Applied Mathematics and Mechanics (English Edition), 31(5), 557-564 (2010).

[8] P. D. Ariel, MHD flow of a viscoelastic fluid past a stretching sheet with suction, Acta Mechanica , Vol. 105,(1-4), pp. 49-56, (1994)

[9] Sujit Kumar Khan , Ioan Pop, Unsteady Free Convective Viscoelastic Boundary Layer Flow Past a Vertical Porous Plate with Internal Heat Generation/Absorption, International Journal of Fluid Mechanics Research, Vol. 33(6), (2006)

[10] M. K. Chowdhury and M. N. Islam, MHD free convection flow of visco-elastic fluid past an infinite vertical porous plate, Heat and Mass Transfer, Vol. 36(5), pp. 439-447, (2000)

[11] Mostafa A. A. Mahmoud, Thermal radiation effect on unsteady MHD free convection flow past a vertical plate with temperature-dependent viscosity, The Canadian Journal of Chemical Engineering, Vo. 87(1), pp. 47-52, (2009)

[12] Kai-Long Hsiao, Heat and mass transfer for electromagnetic viscoelastic flow past a stretching sheet, The 2nd International Conference on Computer and Automation Engineering (ICCAE), Vol. 5, pp. 298-302, Singapore, 26-28 Feb (2010)

[13] Chien-Hsin Chen, Dissipation on Magnetohydrodynamic Flow Past a Permeable, Stretching Surface With Free Convection and Radiative Heat Transfer, J. Heat Transfer Vol. 132( 6), 064501-064503, (2010)

[14] Joaqu í n Zueco;O. Anwar B é g;Swapan K. Ghosh, Unsteady Hydromagnetic Natural Convection of a Short-Memory Viscoelastic Fluid an a Non-Darcian Regime: Network Simulation, Chemical Engineering Communications, Vol. 198(2), pp. $172-190$, (2011)
[15] J. Zueco, "Network simulation method applied to radiation and viscous dissipation effects on MHD unsteady free convection over vertical porous plate," Applied Mathematical Modelling, vol. 31(9), pp. 2019-2033, (2007)

[16] M. Babaelahi, G. Domairry and A. A. Joneidi, Viscoelastic MHD flow boundary layer over a stretching surface with viscous and ohmic dissipations, Meccanica, vol. 45(6), pp. 817-827, (2010)

[17] Mahantesh M. Nandeppanavar, K. Vajravelu and M. Subhas Abe, Heat transfer in MHD viscoelastic boundary layer flow over a stretching sheet with thermal radiation and non-uniform heat source/sink, Communications in Nonlinear Science and Numerical Simulation, Vol. 16(9), pp. 3578-3590, (2011)

[18] M Farzaneh-Gord, A A Joneidi, and B Haghighi, Investigating the effects of the important parameters on magnetohydrodynamics flow and heat transfer over a stretching sheet, JPME258 Proc. IMechE Vol. 224 Part E: J. Process Mechanical Engineering, (2011)

[19] Saleh M. Alharbi, Mohamed A. A. Bazid, Mahmoud S. El Gendy, Heat and Mass Transfer in MHD Visco-Elastic Fluid Flow through a Porous Medium over a Stretching Sheet with Chemical Reaction, Applied Mathematics, 1, (446-455) , (2010).

[20] A. K. Banerjeea A. Vanav Kumara V. Kumarana, Unsteady MHD flow past a stretching sheet due to a heat source/sink, 3rdConference on Nonlinear Science and Complexity, 28 - 31 July, Ankara, Turkey, (2010)

[21] B. I. Olajuwon, Convection heat and mass transfer in a hydromagnetic flow of a second grade fluid in the presence of thermal radiation and thermal diffusion, International Communications in Heat and Mass Transfer, Vol. 38, pp. 337-382, (2010)

[22] R. S. Rivlin and J. L. Ericksen, Stress deformation relations for isotropic materials, J. Rat. Mech. Anal. 4, 323 (1955).

[23] K. R. Rajagopal, T. Y. Na, and A. S. Gupta, Flow of a viscoelastic fluid over a stretching sheet, Rheologica Acta, vol. 23(2), pp. 213-215, (1984)

[24] K. R. Rajagopal and T. Y. Na, On Stokes problem for a non-Newtonian fluid, Acta Mech. 48, 233 (1983). 


\section{التأثير المركب لطاقة التسخين والإتتشار اللزج على الإتتقال الطبيعي للهيروديناميكا المغناطيسية للسوائل اللزجة على الأسطح الرأسية الطبية}

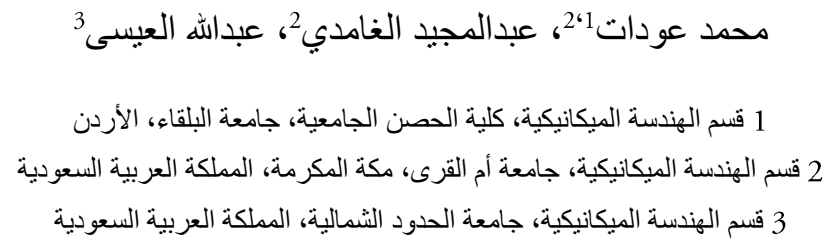

تم في هذا البحث الدراسة النظرية للتأثثر المركب لطاقة التسخين والإنتشار اللزج على الإنتقال الطبيعي للهيدرودوناميكا المغناطيسية للسريان الحر لسائل غير قابل للإنضغاط على أسطح رأسية. تم حل المعادلات الغير خطية المتحكمة في السريان بواسطة طريقة (كر انك-نيكلسون) وتم دراسة عامل اللزوجة والمغناطيسية ورقم "ايكر" ورقم "براندتل" على سريان و إنتقال الحراره. ثم التوصل إلى أن السرعة داخل حدود الطبقات تزداد بزيادة عامل اللزوجة وتبعاً لزيادة معامل الإحتكاك مع الجدران ولوحظ تأثير معاكس لتأثير توزيع الحرارة. 